\title{
Preliminary study of moored power cables
}

\author{
Joana Prat ${ }^{(1)}$, Joaquín del Río( ${ }^{(2)}$, Alejandro Arbos ${ }^{(3)}$ \\ ${ }^{(1)}$ Dept. Matemàtica Aplicada 4. Universitat Politècnica de Catalunya, EPSEVG-UPC. Víctor Balaguer s/n, 08800 \\ Vilanova, Spain \\ ${ }^{(2)}$ SARTI Research Group. Universitat Politècnica de Catalunya, EPSEVG-UPC. Rambla Exposició 24, 08800 Vilanova, \\ Spain \\ ${ }^{(3)}$ Dept. Mecànica de Fluids. Universitat Politècnica de Catalunya, EPSEVG-UPC. Víctor Balaguer s/n. 08800 Vilanova, \\ Spain
}

\begin{abstract}
New green energy sources deployed at sea in mobile platforms use power cables in order to transport generated energy at sea surface to the bottom. Theses power cables are exposed to the dynamic behaviour of the platform movements due to waves, currents and wind. Preliminary simulations of the static and dynamic behaviour of a power cable moored at small depth are done. The study is focused on a static study of cables about 0.1 $m$ diameter in a catenary mooring under different seabed conditions, bending stiffness and cable length. A preliminary dynamic study is also done: the trajectory, tensions and deformation or curvature of such a power cable under a specific periodic wave conditions characteristics of catalan coast, in Mediterraneum, are shown. The static study gives useful information to be used when a dynamic mooring is build. The simulations are done under OrcaFlex software (license N1594).
\end{abstract}

\section{INTRODUCTION}

Simulation of the static and dynamic power cable behavior due to marine conditions is useful to be done before the design and deployment of the cable by a manufacturer, in order to identify critical parameters like forces, effort, elongations and curvature that cable will suffer.

Many bibliography can be found about underwater cables, moorings, buoys, and many simulations exist that study dynamic cables, some of them umbilical cables, in several types of moorings [3,4,6,7]. But few information is found with respect to power cables. It is not easy to get some physic characteristics of power cables like the bending stiffness, because of different layers of cables fitted inside the cable.

The goal of this paper is to show some preliminary results about the behavior of a catenary moored cable under the variation of some parameters like the length of the cable and the seabed friction. Because we don't have a well defined power cable we also consider the bending stiffness as a variable. The paper focus on a bidimensional and static study, which is important before the dynamic simulations are done. A cable fixed to a stable structure and under specific periodic wave movements due to marine conditions in coast of Catalunya is also simulated. Preliminary results are found.

In order to carry out the simulations we use OrcaFlex (version 9.3c) [5], a marine dynamics program developed by Orcina for static and dynamic analysis of a wide range of offshore systems. OrcaFlex provides fast and accurate analysis of umbilical cables under wave and current loads and externally imposed motions. OrcaFlex is a fully 3D non-linear time domain finite element program capable of dealing with arbitrarily large deflections of the flexible from the initial configuration. A lumped mass element is used which greatly simplifies the mathematical formulation and allows quick and efficient development of the program to include additional force terms and constraints on the system in response to new engineering requirements.

The structure of the present paper is the following: a static study of a cable is given in chapter II, with a free end on the seabed and a moored one. In chapter III a preliminary dynamic study is done with the inclusion of periodic sea waves. Finally the conclusions and further work are given in chapter IV.

\section{STATIC STUDY}

A power cable in a catenary mooring at a depth of $15 \mathrm{~m}$ is studied under static conditions with no current, no wind. Systematic simulations are done with a cable of fixed diameter $0.1 \mathrm{~m}$ and weight $22 \mathrm{~kg} / \mathrm{m}$ (see Table I for more details), with the bending stiffness (BS) as a degree of freedom and with no axial stiffness. The cable is limited in a vertical plane measured with coordinates $(\mathrm{x}, \mathrm{z}), \mathrm{x}$ the horizontal one and $\mathrm{z}$ the vertical one (see Fig. 1).

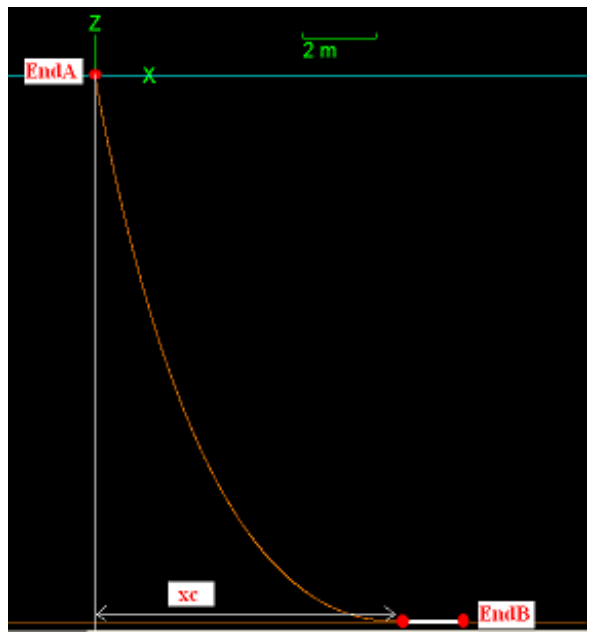

Figure 1. 2D OrcaFlex view of a cable in a catenary mooring. Some notations used in present paper: EndA means the point at the top of cable on sea surface, EndB means the end point of cable on seabed, $\mathrm{x}_{\mathrm{c}}$ means the $\mathrm{x}$-coordinate of contact point of cable to seabed. 
TABLE I. Fixed parameters used in OrcaFlex simulations (static case).

\begin{tabular}{|c|c|c|}
\hline Parameter & Value & Units \\
\hline Sea density & 1025 & $\mathrm{~kg} / \mathrm{m}^{3}$ \\
\hline Kinematic viscosity & $1.35 \times 10^{-6}$ & $\mathrm{~m}^{2} / \mathrm{s}$ \\
\hline Cable diameter & 0.1 & $\mathrm{~m}$ \\
\hline Cable weight per meter & 22 & $\mathrm{~kg} / \mathrm{m}$ \\
\hline Cable axial stiffness & $700 \times 10^{3}$ & $\mathrm{kN}$ \\
\hline Cable Poisson ratio & 0.5 & \\
\hline Cable torsional stiffness & 80 & $\mathrm{kNm}^{2}$ \\
\hline Cable drag coefficients ( $\mathrm{x}$ and $\mathrm{z}$ ) & 1.2 and 0.008 & \\
\hline
\end{tabular}

TABLE II. Variation of parameters used in OrcaFlex simulations (static case).

\begin{tabular}{|l|l|l|}
\hline \multicolumn{1}{|c|}{ Parameter } & \multicolumn{1}{c|}{ Value } & Units \\
\hline Friction coefficient 1 (F1) & 0.005 & \\
\hline Friction coefficient 2 (F2) & 0.25 & \\
\hline Cable length 1 (L1) & 20 & $\mathrm{~m}$ \\
\hline Cable length 2 (L2) & 45 & $\mathrm{~m}$ \\
\hline Bending stiffness 1 (BS1) & 0.1 & $\mathrm{kN} / \mathrm{m}^{2}$ \\
\hline Bending stiffness 2 (BS2) & 0.7 & $\mathrm{kN} / \mathrm{m}^{2}$ \\
\hline Bending stiffness 3 (BS3) & 7 & $\mathrm{kN} / \mathrm{m}^{2}$ \\
\hline $\mathrm{X}_{\text {EndB 1 }}$ & 38 & $\mathrm{~m}$ \\
\hline $\mathrm{X}_{\text {EndB 2 }}$ & 40 & $\mathrm{~m}$ \\
\hline $\mathrm{X}_{\text {EndB 3 }}$ & 41 & $\mathrm{~m}$ \\
\hline & \multicolumn{2}{|l}{} \\
\hline
\end{tabular}

The study is done with respect to two different seabed conditions: a sandy seabed and a sliding seabed with almost no friction. These conditions are applied with a seabed friction coefficient using Coulomb friction (see OrcaFlex Manual v. 9.3a), the data used follows recommendations of Taylor and Valent [1984] (see the values in Table II). Other parameters of the cable are varied: the bending stiffness is moved from 0.1 to $7 \mathrm{kN} / \mathrm{m}^{2}$ and length values of $20 \mathrm{~m}$ and $45 \mathrm{~m}$ are used, those are cable lengths with ratio $\mathrm{r}=$ length/depth 1.33 and 3 respectively (see Table II for more details).

The study is focused with respect to the total tension at the top of the cable on the sea surface (from now EndA point), the tension at the end of cable on the seabed (from now EndB point), the maximum curvature along the cable, the contact point of the cable to the seabed, in particular the $\mathrm{x}$-coordinate $\mathrm{x}_{\mathrm{c}}$ (see Fig.1) and the \% of length of cable without seabed contact. Two cases are simulated: one with a free EndB point and the other one with a fixed EndB point. The OrcaFlex simulations are done with segments of cable of $0.2 \mathrm{~m}$, small enough to detect accurately the seabed contact with cable.

\section{A. Results with a free end of cable}

With respect to the total tension of the cable (see Fig. 2 (a)): in every case the total tension keeps the same order of magnitude when a variation of the bending stiffness is imposed. When the seabed friction is very small the tensions do not change when the cable length is increased, it is about $2.05 \mathrm{kN}$. However it increases when a sandy seabed is considered, it is about $2.20 \mathrm{kN}$ with small cable length and it increases to 2.90 $\mathrm{kN}$ when the length of the cable is 3 times depth $(\mathrm{r}=3)$. Obviously the total tension at the end of the cable is 0 . (a)

(b)

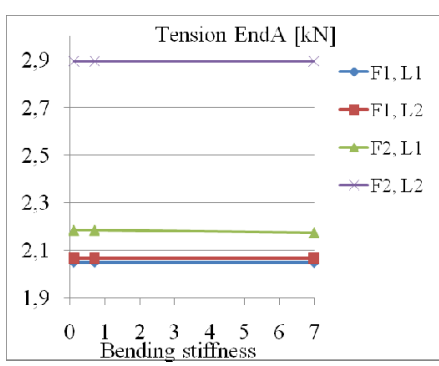

(c)

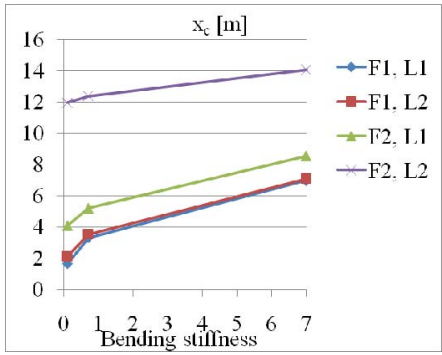

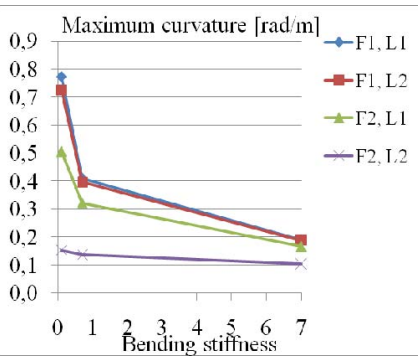

(d)

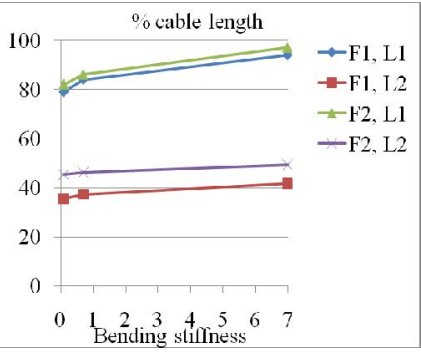

Figure 2. Different results of simulations with a static free cable as a function of the bending stiffness $\left[\mathrm{kN} / \mathrm{m}^{2}\right]$ for different conditions of friction and cable length (see Table II to get values). (a) Total tension of the cable at EndA [kN]. (b) Maximum curvature along the cable $[\mathrm{rad} / \mathrm{m}]$. (c) x-coordinate of cable to seabed contact, $\mathrm{x}_{\mathrm{c}}[\mathrm{m}]$. (d) \% of cable length without contact to seabed.

As expected the maximum curvature along the cable decreases when bending stiffness increases (see Fig. 2 (b)). When a sliding seabed is considered the shape of the cable does not change significantly with different cable lengths as can be deduced from Fig. 2 (b) and (c). When a seabed friction is imposed the catenary of cable changes significantly when the cable length changes (see the maximum curvature along cable and $\mathrm{x}_{\mathrm{c}}$ coordinate of seabed contact point in Fig. 2 (b) and (c)).

A range of about $80 \%-95 \%$ of cable length does not have seabed contact when the ratio is $\mathrm{r}=1.33$, meanwhile this range changes to $35 \%-50 \%$ when $\mathrm{r}=3$, with and without seabed friction, a little bit bigger with friction as can be observed in Fig. 2 (d).

As a consequence of these results the equilibrium position of EndB point is found in static state, i.e. the location of the end of the cable on the seabed. In Fig. 3 the horizontal coordinate $\mathrm{X}_{\text {EndB }}[\mathrm{m}]$ is shown. When a ratio $\mathrm{r}=1.33$ is considered then EndB point stands 6 to 9 meters from the vertical of EndA. When $\mathrm{r}=3$, then $\mathrm{x}_{\mathrm{EndB}}$ increases to 31 to 33 meters with no friction and to about 37 meters with a sandy seabed and in the latest case do not change significantly with the bending stiffness. 


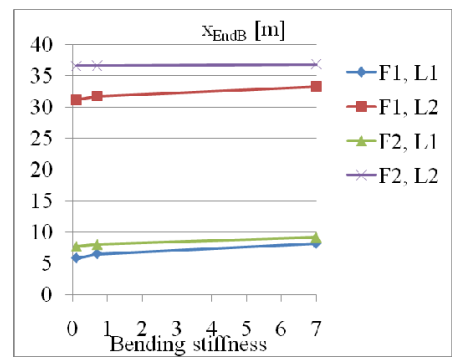

Figure 3. Horizontal $\mathrm{x}$-coordinate of EndB (the end of cable on seabed), $\mathrm{x}_{\mathrm{EndB}}$ $[\mathrm{m}]$ as a function of the bending stiffness $\left[\mathrm{kN} / \mathrm{m}^{2}\right]$ for different conditions of friction and cable lengths (see Table II to get values).

\section{B. Results with a moored cable}

A cable with a free end is the ideal scenario taking into account the tensions: we wish a moored cable with no tension at the EndB point. This means that the suitable location of EndB is important. In this section we focus with case $r=3$ and we study how the tensions increase when we force a moored cable further than the equilibrium position with a free end, in particular the cable is moored in 3 different extreme positions with horizontal $\mathrm{x}_{\mathrm{EndB}}$ coordinates 38,40 and $41 \mathrm{~m}$ (see Table II). Fig. 4 shows the results of tensions, seabed contact point and cable length lying on a sliding seabed. As can be shown in Fig. 4 (a) and (b) the bending stiffness of cable do not affect to the resultant tensions. In case $\mathrm{x}_{\mathrm{EndB} 1}$ the tension at EndB is about $1.4 \mathrm{kN}$, in case $\mathrm{x}_{\mathrm{EndB} 2}$ it increases to $3.4 \mathrm{kN}$ and in the extreme case $\mathrm{x}_{\mathrm{EndB} 3}$ it supports a tension of about $5.7 \mathrm{kN}$, four times bigger than first case with only 3 meters of difference.

It is interesting to compare the total tension of a moored cable with respect to a free one studied in section II-A. Table III shows both results and last column shows the difference of total tension. When a sliding seabed is tested (F1 as a friction coefficient) then the total tension is increased with approximately the tension at EndB, see $5^{\text {th }}$ column and the last one.

The seabed contact point moves about $15 \mathrm{~m}$ away when the fixed position of EndB is changed from 1 to 3 case (see Fig. 4 (c)). Meanwhile the cable length on seabed changes from about $20 \mathrm{~m}$ to about only $6 \mathrm{~m}$ (see Fig. 4 (d)). The corresponding $\%$ of cable lengths without seabed contact changes from about $56 \%$ to a critical $87 \%$. The comparison with a static cable with free end (see Fig. 2 (d)) showed a maximum of $50 \%$ of cable length with no seabed contact.

The results with a sandy seabed are not represented in Fig. 4, a coincidence between results of both seabed types is found (see Table III), only minor differences with respect to the tension at the EndB point from $1.1 \mathrm{~N}$ to $3.6 \mathrm{~N}$ are found (see Fig. 5). Table IV also shows the comparison of some results when bounding stiffness is $0.1 \mathrm{kN} / \mathrm{m}^{2}$ and $\mathrm{x}_{\mathrm{EndB}}=38 \mathrm{~m}$. (a)

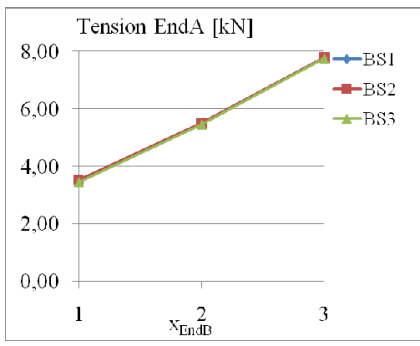

(c)
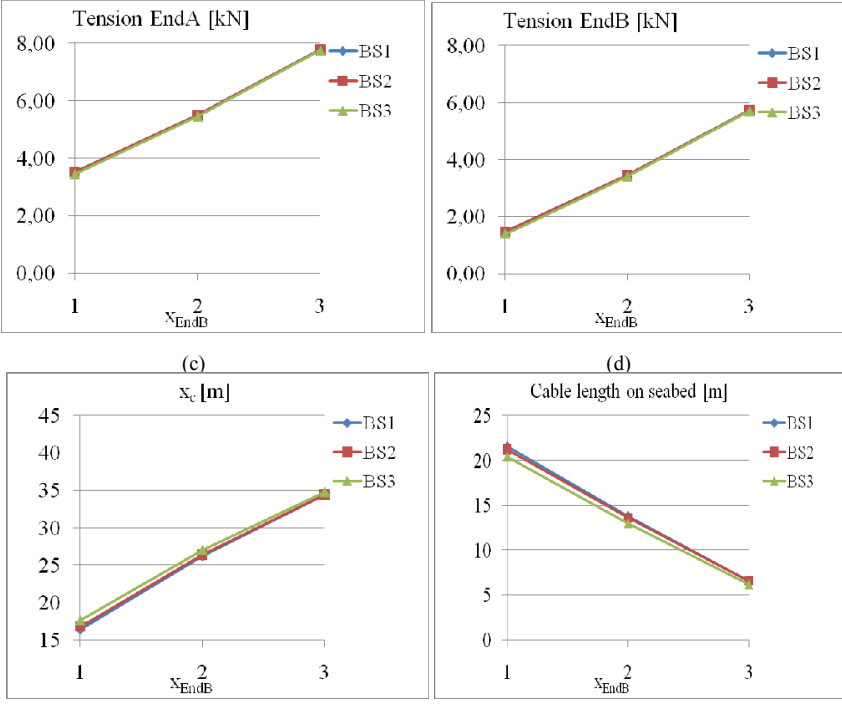

(d)

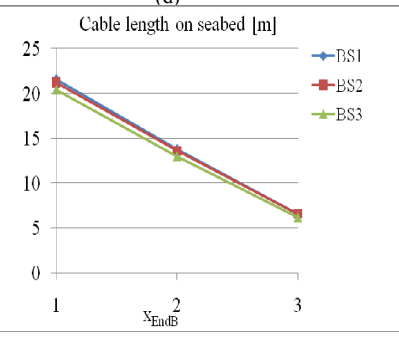

Figure 4. Different results of simulations with a static moored cable as a function of the EndB position for different conditions of bending stiffness in a sliding seabed, case $\mathrm{r}=3$ (see Table II). (a) Total tension of the cable at EndA [kN]. (b) Total tension of the cable at EndB [kN]. (c) x-coordinate of cable to seabed contact, $x_{c}[\mathrm{~m}]$. (d) Length of cable lying on seabed $[\mathrm{m}]$.

TABLE III. Comparison of results between a free cable and a moored or fixed one when $\mathrm{r}=3$. F means friction coefficient and BS bounding stiffness (see

\begin{tabular}{|c|c|c|c|c|c|c|c|}
\hline $\mathrm{F}$ & BS & $\begin{array}{c}\text { Tension } \\
\text { EndA } \\
\text { Free } \\
{[\mathrm{kN}]}\end{array}$ & $\begin{array}{c}\text { Tension } \\
\text { EndA } \\
\text { Fixed } \\
{[\mathrm{kN}]}\end{array}$ & $\begin{array}{c}\text { Tension } \\
\text { EndB } \\
\text { Fixed } \\
{[\mathrm{kN}]}\end{array}$ & $\begin{array}{l}\mathrm{X}_{\text {EndB }} \\
\text { Free } \\
{[\mathrm{m}]}\end{array}$ & $\begin{array}{c}\mathrm{X}_{\text {EndB }} \\
\text { Fixed } \\
{[\mathrm{m}]}\end{array}$ & $\begin{array}{c}\text { Diff. Tension } \\
\text { EndA } \\
\text { Fixed-Free } \\
{[\mathrm{kN}]}\end{array}$ \\
\hline \multirow{3}{*}{ F1 } & BS1 & 2.066 & 3.532 & 1.473 & 31.2 & 38 & 1.4656 \\
\hline & BS2 & 2.0656 & 3.524 & 1.464 & 31.7 & 38 & 1.4580 \\
\hline & BS3 & 2.0658 & 3.448 & 1.388 & 33.3 & 38 & 1.3826 \\
\hline \multirow{3}{*}{$\mathrm{F} 2$} & BS1 & 2.8937 & 3.532 & 1.442 & 36.6 & 38 & 0.6380 \\
\hline & BS2 & 2.8937 & 3.524 & 1.434 & 36.6 & 38 & 0.6299 \\
\hline & BS3 & 2.8945 & 3.448 & 1.363 & 36.9 & 38 & 0.5538 \\
\hline
\end{tabular}

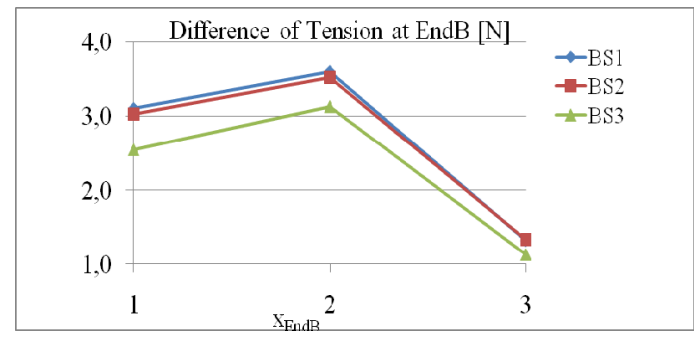

Figure 5. Difference of tensions $[\mathrm{N}]$ at EndB between two different seabed conditions (which correspond to a F1 and F2 friction coefficient, see Table II).

TABLE IV. Comparison between different seabed conditions of the tensions at EndA and EndB points when $\mathrm{x}_{\mathrm{EndB}}=38 \mathrm{~m}$ and bending stiffness BS1.

\begin{tabular}{|l|c|c|c|c|}
\hline $\begin{array}{c}\text { Friction } \\
\text { coefficient }\end{array}$ & $\begin{array}{c}\text { Tension } \\
\text { EndA } \\
{[\mathrm{kN}]}\end{array}$ & $\begin{array}{c}\text { Tension } \\
\text { EndB } \\
{[\mathrm{kN}]}\end{array}$ & $\begin{array}{c}\mathrm{x}_{\mathrm{c}} \\
{[\mathrm{m}]}\end{array}$ & $\begin{array}{c}\text { Cable length } \\
\text { on seabed } \\
{[\mathrm{m}]}\end{array}$ \\
\hline $\mathrm{F} 1$ & 3.532 & 1.473 & 16.4 & 21.6 \\
\hline $\mathrm{F} 2$ & 3.532 & 1.442 & 16.4 & 21.6 \\
\hline
\end{tabular}


When a comparison between a free cable and a moored in a sandy seabed is done then a smaller difference of total tension is found, at about $0.6 \mathrm{kN}$ of difference instead of about $1.4 \mathrm{kN}$ (see Table III, last column).

\section{DYNAMIC STUDY}

An example of a 2D moored cable subjected to periodic waves has been simulated. The study is focused with a $45 \mathrm{~m}$ length power cable with bending stiffness $7 \mathrm{kN} / \mathrm{m}^{2}$ (see other properties in Table I) moored at a $15 \mathrm{~m}$ depth. The idea is to simulate the behavior of a power cable in Tarragona coast, middle-south coast of Catalunya. The reason for doing this is because we have official data of a coast buoy moored at $15 \mathrm{~m}$ depth in Tarragona coast, data from "Puertos del Estado" of Spanish Government (see Fig. 6 and web side: http://www.puertos.es/ca/oceanografia_y_meteorologia/banco_ de_datos/index.html). Data was collected from December 2008 to January 2009. A mean value of significant height of wave about 0.5 meters with a period of 5 seconds is found (using a statistical study), meanwhile a maximum significant height about 2.23 meters and period 7 seconds is found. The calculations are done using the latest case.

The model is limited to a 2D study --we consider sea waves with the direction included in the vertical plane containing the cable. The study is limited to periodic sea waves, nor sea current neither wind are considered.

The idea is to model a power cable under a suitable platform, which should give stability to the whole structure. The present study is limited to the cable behavior; this study is very preliminary, as a first approach we consider a big vessel of length $103 \mathrm{~m}$ (the Type1 defined in OrcaFlex environment).

The first 2 meters of cable, linked to the vessel, are rigid and vertical with a diameter of $0.2 \mathrm{~m}$, mass of $180 \mathrm{~kg} / \mathrm{m}$, bending stiffness of $700 \mathrm{kN} / \mathrm{m}^{2}$ (see Fig. 7). The EndA is located at $6 \mathrm{~m}$ of depth, in position $(0,-6)$ in local axis $(x, z)$ with meters as units.

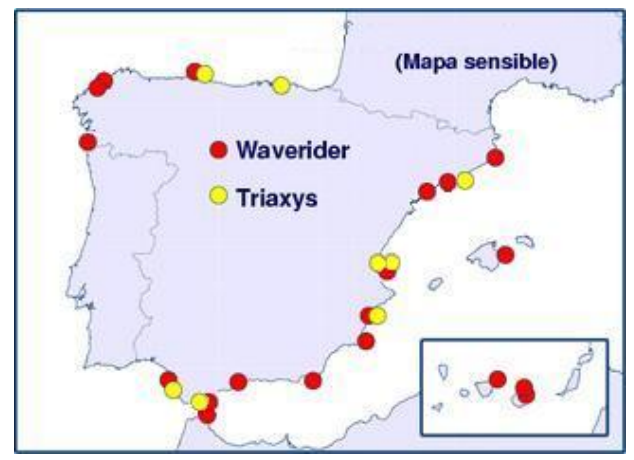

Figure 6. Coast buoys with official data from Spanish Government. The red ones with wave information, the Tarragona buoy is located in catalan coast, on North-West (the forth one circle from the top).

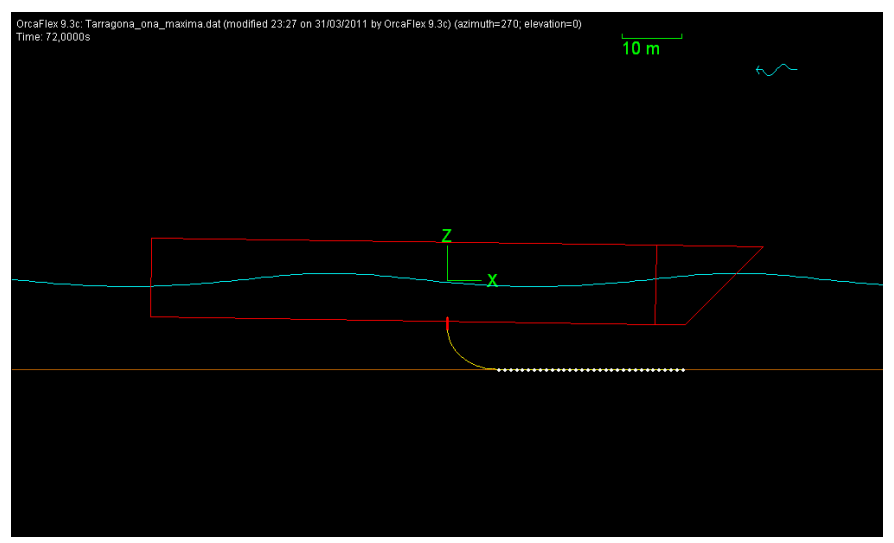

Figure 7. OrcaFlex model of a dynamic cable attached to a stable structure (vessel) subjected to periodic waves. Cable moored at depth $45 \mathrm{~m}$, with $45 \mathrm{~m}$ length, with properties shown in Table I.

The cable is moored assuming static state, as result of a static simulation with free end, in order to have no resistance at EndB.

The results we are going to focus are: the effective tension or total tension (tension at EndA), the curvature, the orbit of EndA, the position of cable as a function of time and as a function of arc length of cable. All these parameters are important to design the cable, anchorage of cable to the platform and inclusion of local buoys among others.

Fig. 8 shows temporal results of total tension and $(x, z)$ components of EndA point. The structure inherits the periodicity of sea behavior. The tension of cable is around 4 $\mathrm{kN}$, we observe a bigger tension than in static case with same conditions (2.9 $\mathrm{kN}$ in static case, see Fig. 2), this is probably due to the extra $2 \mathrm{~m}$ rigid part of cable in comparison of the static one. The variation of tension is less than $1 \mathrm{kN}$, the movement of EndA is less than $2 \mathrm{~cm}$ in the horizontal and than $8 \mathrm{~cm}$ in the vertical.

Fig. 9 shows the periodic orbit that describes EndA around the static position $(0,-6)$, it reminds an ellipse. This graphic confirms the periodicity inherits by the structure.

Fig. 10 shows the range of variation of tension, curvature and vertical component of cable along the cable.

A careful study of results shown in Fig. 10 (a) we can find a maximum deviation of tension at arc length $8.85 \mathrm{~m}(2 \mathrm{~m}$ of them are the rigid part on the top of cable). The same result is found in curve of curvature in Fig. 10 (b). Another part of the cable located at $14.55 \mathrm{~m}$ of arc length has a big deviation, but this is because the cable touch seabed depending of the oscillation (see Fig. 10 (c)). A bigger change in tension and curvature means that a bigger instability is found in that part of the dynamic cable. As a consequence the design of this cable-structure should improve, one could try to reinforce with other material or help with local buoys the more unstable part of dynamic cable or change components of structure. 
(a)

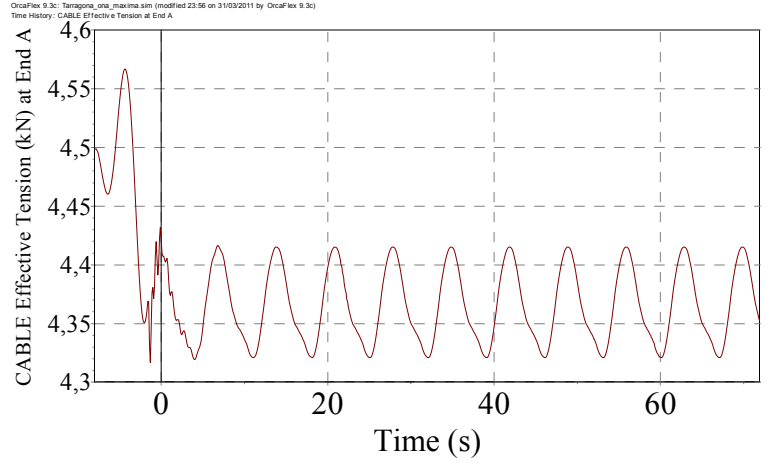

(b)

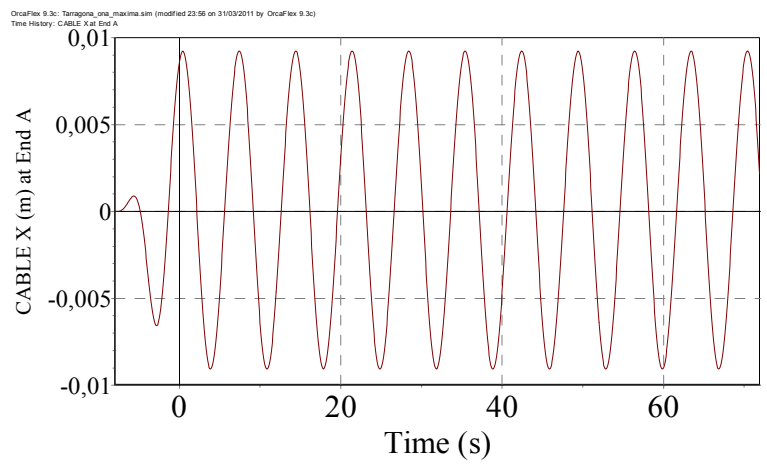

(c)

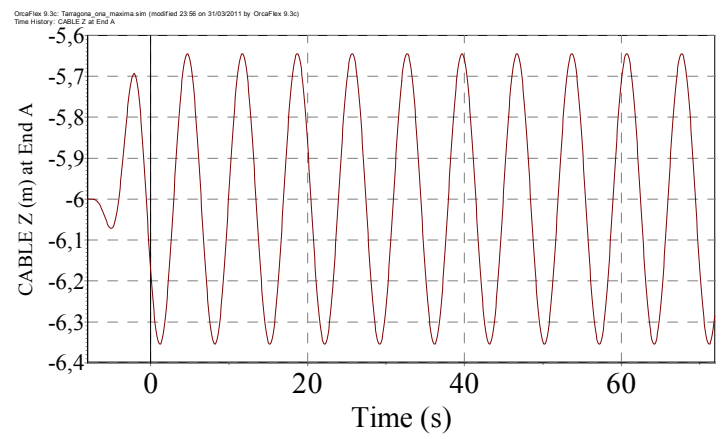

Figure 8. Different results of dynamic simulation of structure in Figure 6 as a function of time. Periodic waves with $2.23 \mathrm{~m}$ height and $7 \mathrm{~s}$ of period. (a) Total tension of the cable at EndA $[\mathrm{kN}]$, (b) Horizontal position $\mathrm{x}$ of EndA [m], (c) Vertical position $\mathrm{z}$ of EndA [m].

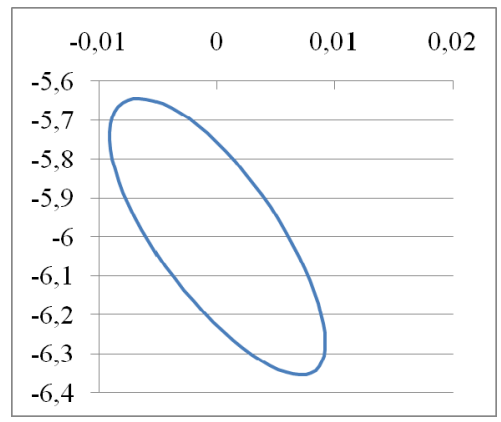

Figure 9. $(\mathrm{x}, \mathrm{z})$ plot of components of EndA of dynamic simulation of structure in Fig. 6 as a function of time. Periodic waves with $2.23 \mathrm{~m}$ height and $7 \mathrm{~s}$ of period. Units of axis are $[\mathrm{m}]$.

(a)

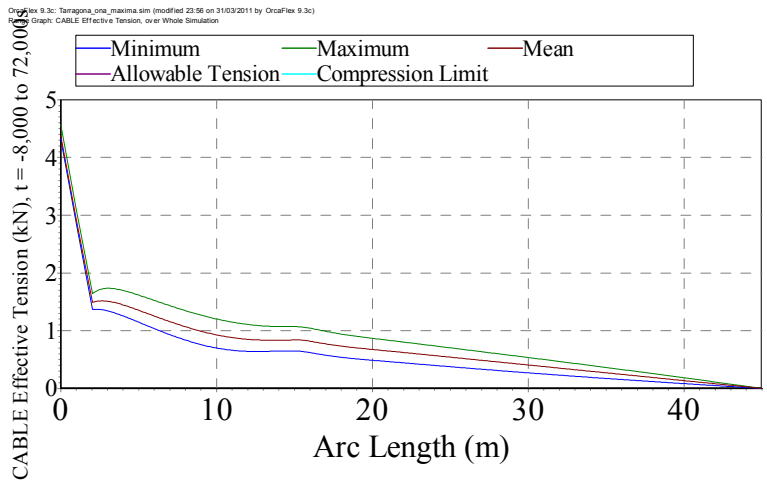

(b)

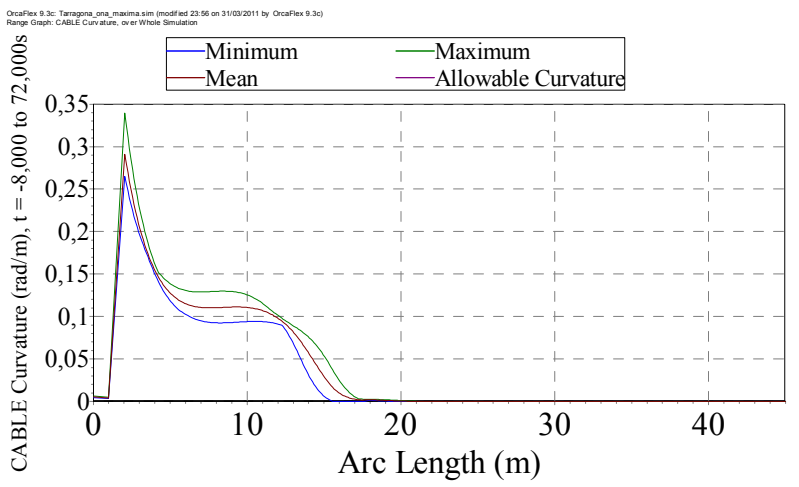

(c)

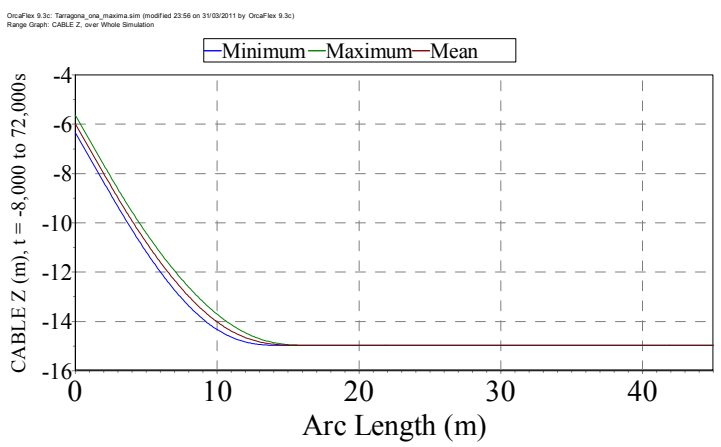

Figure 10. Different results of dynamic simulation of structure in Figure 6 as a function of arc length of cable. Periodic waves with $2.23 \mathrm{~m}$ height and $7 \mathrm{~s}$ of period. (a) Tension of the cable $[\mathrm{kN}]$, (b) Curvature $[\mathrm{rad} / \mathrm{m}]$ of the cable, (c) Vertical position $\mathrm{z}$ of the cable $[\mathrm{m}]$. 


\section{CONCLUSIONS}

From this preliminary and systematic study of catenary moored power cables we can conclude some important topics about a power cable deployment. The static simulation from a cable and seabed parameters with a free EndB cable, is very important in order to define what will be the fixed position of EndB point. A small difference of EndB point out of its static position can multiply by four the EndB tension.

Once the cable is EnbB fixed, the seabed friction doesn't affect, but it will be very important to define the static situation.

An increase of the seabed friction also affects to an increment of the total tension of cable when the EndB is free. Some of the simulations results were expected, but a systematic approach was needed in order to evaluate them. Differences in total tension (see Table III) with respect to different seabed frictions are due to seabed contact resistance of the cable.

About dynamic simulation, it is important to show that surface structure inherited the wave's periodicity, and EndA point describes an orbit that reminds an ellipse around the static position. The study of the range of tension and curvature variation along the cable gives information about the more unstable cable segments. The ongoing simulations wants to define how stabilize these unstable segments with a reinforcement. Future work will focus on a systematic study with different waves, wind and current parameters as well as different depths.

\section{ACKNOWLEDGMENT}

J.P. thanks financial support under grant CICYT number DPI2008-01408 from Prof. Carles Batlle.

J.dR thanks financial support under grant CICYT number ACI2009-0983 from MICINN.

\section{REFERENCES}

[1] Batchelor, George (2000). An introduction to fluid dynamics. Cambridge Mathematical Library (2 ${ }^{\text {nd }}$ ed.). Cambridge University Press. MR1744638 (http://www.ams.org/mathscinetgetitem?mr=1744638). ISBN 978-0-521-66396-0

[2] DNV, 1991. Environmental Conditions and Environmental Loads Classification Notes 30.5 March

[3] Gobad, J.I., and Grosenbaugh, M.A., 2006, Time-domain numerical simulation of ocean cable structures, Ocean Eng., 33:1373-1400.

[4] Goodman, T.R., and Breslin, J. P., 1976, Statics and dynamics of anchoring cables in waves, J Hydronautics, 10(4):113-120.

[5] Orcaflex Manual: Online at http://www.orcina.com/SoftwareProducts/OrcaFlex/Documentat ion/OrcaFlex.pdf

[6] Paul, W., Irish, J., Gobad, J.I., Grosenbaugh, M.A., 1999, Coastal mooring design: taut elastomeric and chain catenary surface buoy moorings. Oceans '99:419-426.
[7] Taylor R. and Valent P., 1984. Design Guide for Drag Embedment Anchors, Naval Civil Engineering Laboratory (USA) TN No N-1688. 